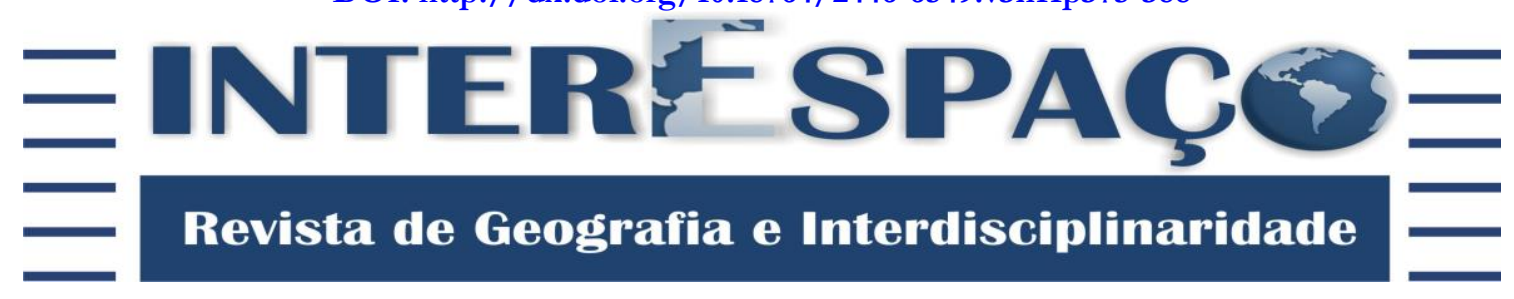

\title{
QUALIDADE DE VIDA NO TRABALHO DE PROFESSORES DA EDUCAÇÃO BÁSICA: revisão integrativa
}

\author{
QUALITY OF LIFE IN THE WORK OF TEACHERS OF BASIC EDUCATION: \\ integrative review
}

\section{CALIDAD DE VIDA EN EL TRABAJO DEL PROFESORADO DE EDUCACIÓN BÁSICA: revisión integradora}

\begin{abstract}
Alda Dantas do Rêgo
Mestra em Gestão e Desenvolvimento Regional pela Universidade de Taubaté - UNITAU. Graduada em Matemática pela Universidade Estadual do Maranhão - UEMA. adandyou36@gmail.com

Adriana Leônidas de Oliveira

Doutora em Psicologia pela Pontifícia Universidade Católica de São Paulo - PUC/SP e Pósdoutorado em Administração pela EAESP- FGV-SP. Professora do Programa de Pós-Graduação em Gestão e Desenvolvimento Regional da Universidade de Taubaté - UNITAU. adrianaleonidas@uol.com.br

Recebido para avaliação em 23/02/2017; Aceito para publicação em 01/03/2018.

\section{RESUMO}

Este estudo objetivou verificar as publicações nacionais que investigaram a situação da qualidade de vida no trabalho de professores da educação básica que atuam na rede pública de ensino, por meio da revisão integrativa de pesquisas científicas. Os professores estão constantemente expostos às situações de riscos psicossociais e enfrentam diariamente situações de desmotivação e desvalorização profissional. Foi realizada uma revisão integrativa de literatura e as informações foram coletadas nas bases de dados: Literatura Latino-Americana e do Caribe em Ciências da Saúde (LILACS), Scientific Electronic Library Online (SCIELO) e Periódicas Capes: Revista Evidência e Revista Brasileira em promoção da Saúde. Foram consultados artigos publicados do período de 2006 a 2016, utilizando as palavras-chave: "qualidade de vida", "trabalho", "professores", "educação básica". Foram encontrados 21 artigos e, entre estes, apenas cinco preencheram devidamente os critérios de inclusão para o estudo. Os resultados evidenciaram que os artigos analisados utilizaram os mesmos instrumentos e retratam as vulnerabilidades dos professores. Observou-se que há carência de políticas públicas que intervém no ambiente de trabalho dos professores, além de um baixo número de produções científicas no Brasil sobre o tema.
\end{abstract}

Palavras-chave: Qualidade de Vida; Trabalho; Professor; Educação Básica.

\begin{abstract}
This study aimed to verify national publications that investigated the quality of life situation in the work of teachers of basic education who work in the public school system, through an integrative review of scientific research. Teachers are constantly exposed to situations of psychosocial risks and face daily situations of demotivation and professional devaluation. An integrative literature review was carried out, the information was collected in the databases: Latin American and Caribbean Literature in Health Sciences (LILACS), Scientific Electronic Library Online (SCIELO) and Periódicas Capes: Revista Evidência e Revista Brasileira em destaque Of health. Articles published
\end{abstract}


Dossiê: Diálogos interdisciplinares em Psicologia da Educação

| Qualidade de vida no trabalho de professores da Educação Básica: revisão integrativa |

|Alda Dantas do Rêgo | Adriana Leônidas de Oliveira |

from 2006 to 2016 were used, using the key words: "quality of life", "work", "teachers", and "basic education". We found 21 articles, and among these, only 5 adequately met the inclusion criteria for the study. The results showed that the analyzed articles used the same instruments and portrayed the vulnerabilities of teachers. It was observed that there is a lack of public policies that intervene in the work environment of the teachers and there are a few scientific productions in Brazil on the subject.

Keywords: Quality of Life; Job; Teacher; Basic Education.

\section{RESUMEN}

Este estudio tuvo como objetivo verificar las publicaciones nacionales que investigaron la situación de la calidad de vida en el trabajo de los maestros de educación básica que trabajan en las escuelas públicas, a través de la revisión integradora de la investigación científica. Los maestros están constantemente expuestos a situaciones de riesgos psicosociales y se enfrentan a situaciones cotidianas de la desmotivación y la devaluación profesional. una revisión integradora de la literatura se llevó a cabo, la información que se recoge en las bases de datos: América Latina y el Caribe Ciencias de la Salud (LILACS), Scientific Electronic Library Online (SciELO) y capas periódicas: Revista Evidencia y Revista Internacional de la venta. Salud se consultó a los artículos publicados en el periodo 2006-2016, utilizando las palabras clave "calidad de vida", "trabajo", "maestro", "educación básica". Encontraron 21 artículos, y entre éstos, sólo 5 cumplen adecuadamente los criterios de inclusión para el estudio. Los resultados mostraron que los artículos analizados, utilizan los mismos instrumentos y muestran la vulnerabilidad de los maestros. Se observó que existe una falta de políticas públicas que intervienen en el entorno de trabajo de los profesores y hay un bajo número de producciones científicas en Brasil sobre el tema

Palabras clave: Calidad de Vida; Trabajar; El profesor; La Educación Básica.

\section{INTRODUÇÃO}

Cada vez mais, as preocupações com a qualidade de vida no trabalho vêm propiciando às organizações mecanismos que viabilizem motivações e oportunidades com hábitos saudáveis entre trabalhadores e gestão. Neste contexto, é perceptível que a satisfação com o ambiente do trabalho proporciona melhorias na produtividade.

Sabe-se que as problemáticas centrais sobre a qualidade de vida no trabalho são elevadas, principalmente na área da educação básica. Como a qualidade de vida no trabalho está relacionada, a priori, à saúde e ao bem-estar do indivíduo, buscam-se alternativas de melhorias para ocorrências quanto aos riscos tanto físicos quanto mentais dos trabalhadores.

Dessa forma, observou-se nas investigações realizadas sobre a qualidade de vida de professores da rede pública - educação básica, a utilização de vários instrumentos para coleta de dados, como a Escala de Avaliação de Qualidade de Vida no Trabalho (QVTPEF), entrevistas, Whoqol-bref e Critério de Classificação Econômica. No entanto, a maioria dos instrumentos utilizados procuram abordar aspectos relacionados ao estilo de 
|Alda Dantas do Rêgo | Adriana Leônidas de Oliveira |

vida e à saúde dos indivíduos, deixando uma lacuna para parâmetros afetos à satisfação e ao bem-estar no ambiente do trabalho desses professores.

Sob esta ótica, os professores da educação básica estão expostos à condições de trabalho vulneráveis, à rotina de trabalho excessiva, ao desgaste físico, mental, profissional e emocional que acarretam à categoria doenças psicológicas. A qualidade de vida no trabalho associada aos professores traz a necessidade de uma verificação de como esses profissionais percebem a satisfação no seu ambiente de trabalho, bem-estar profissional e pessoal, saúde e estilo de vida.

Tais fatores envolvem e proporcionam aos professores mecanismos de inovação quanto à satisfação e ao bem-estar no que fazem. Neste contexto, os autores Rueda, Lima e Raad (2014) definem bem a satisfação no trabalho: “é construto múltiplo e composto por diferentes fatores que se inter-relacionam”. Assim, qualidade de vida no trabalho pode ser definida como a técnica utilizada para o enriquecimento no trabalho dos professores, com a realização de atividades em grupos que gerem a inter-relação entre os trabalhadores.

Para elaboração do presente estudo, foi realizada uma busca nas bases de dados nacionais (Periódicos Capes, LILACS, SciELO), e considerou-se os constructos que relacionam-se à qualidade de vida no trabalho de professores.

Reconhecendo a relevância acadêmica e social, o artigo em questão, por meio de uma revisão integrativa de produções científicas brasileiras, teve por objetivo verificar as possíveis publicações nacionais que investigaram a situação da qualidade de vida no trabalho de professores da educação básica que atuam na rede pública.

\section{QUALIDADE DE VIDA NO TRABALHO (QVT)}

Nas últimas décadas, a qualidade de vida no trabalho tem protagonizado um papel importante, principalmente na área da saúde (PEREIRA, 2013; TABELEÃO; TOMASI; NEVES, 2011; HOLMES et al., 2014; MOREIRA et al., 2009). Neste contexto, os fatores de risco no trabalho estão relacionados à competitividade, que propicia vulnerabilidade aos indivíduos, favorecendo a incidência e comprometendo a saúde dos trabalhadores.

Embasados em Mendonça e Araújo (2016) e Moreira et al. (2010), destaca-se que a qualidade de vida no trabalho, nessa conjuntura, viabiliza a promoção de bons hábitos que favoreçam e facilitem, nos espaços de trabalho, uma importante gestão de recursos humanos, desde que exista sensibilidade para detectar condições favoráveis e motivadoras para os trabalhadores em atividades. 
Dossiê: Diálogos interdisciplinares em Psicologia da Educação

| Qualidade de vida no trabalho de professores da Educação Básica: revisão integrativa |

|Alda Dantas do Rêgo | Adriana Leônidas de Oliveira |

A qualidade de vida no trabalho nas organizações funciona com a prática de melhorias e estratégias, uma forma de "assistencialismo" prestado aos trabalhadores, almejando ganho de produtividade pelas organizações. França (1997) destaca que a qualidade de vida no trabalho é identificada por um conjunto de ações que uma determinada empresa presta, pois "envolve a implantação de melhorias em inovações gerenciais e tecnológicas no ambiente de trabalho". Essas ações disponibilizadas pelas organizações se configuram muito mais como atividades motivadas pela produtividade do que pelo bem-estar dos trabalhadores.

De acordo com França (1997), a "construção da qualidade de vida no trabalho ocorre a partir do momento em que se olha a empresa e as pessoas como um todo". A autora considera essa relação como sendo um "enfoque biopsicossocial", pois permite o marco diferencial que viabiliza um diagnóstico para a prevenção e o desenvolvimento dos indivíduos no trabalho, dentro da organização.

Com sucessivas ocorrências e manifestações dos trabalhadores no século XX, vários estudiosos de diversas áreas foram impulsionados a pesquisar as condições no ambiente de trabalho relacionadas aos trabalhadores. Com essas manifestações, surgem os primeiros registros sobre a qualidade de vida no trabalho. Essa denominação surgiu na Inglaterra na década de 1950; segundo Rodrigues (2016), a partir dessa década encontramse registros das primeiras teorias associadas à produtividade, à satisfação, ao bem-estar e ao bom desenvolvimento do trabalhador.

Neste contexto histórico, embora o tema qualidade de vida no trabalho possa parecer recente, o homem, desde o início de sua existência, tem procurado meios que lhe proporcionem satisfação e bem-estar no exercício de sua atividade.

O termo qualidade de vida no trabalho ganhou destaque no cenário nacional a partir da década de 1970, passando a ser pesquisado em vários países. Entretanto, de acordo com Rodrigues (2016), somente a partir de 1980 surgiram registros de pesquisas no Brasil com o intuito de readaptação de "modelos estrangeiros", a fim de construir um modelo que estivesse em conformidade com as viabilidades culturais brasileiras.

Atualmente, preocupações com o bem-estar e com a saúde do indivíduo nas organizações vêm ganhando espaço e potencialidade, sendo que doenças ocupacionais tendem, ocasionalmente, à redução na produtividade, pois o trabalhador, hoje, cumpre uma carga horária média de 10 horas diárias dedicadas à vida laboral, o que resulta no adoecimento atrelado às condições de trabalho. 
|Alda Dantas do Rêgo | Adriana Leônidas de Oliveira |

\section{PROFESSORES E QUALIDADE DE VIDA NO TRABALHO}

A qualidade de vida no trabalho tem sido um tema com abrangência significativa para a classe trabalhista e discutido por diversas áreas de pesquisas. Contudo, a qualidade de vida no trabalho dos professores, em especial, os que atuam principalmente na educação básica, tem sido pouco investigada. Both et al. (2006), em pesquisa sobre a qualidade de vida de professores, apontam uma "escassez e superficialidades de estudos nesta temática".

Vive-se em uma época em que grandes mudanças sociais e culturais são transformadas pelas forças dos avanços tecnológicos, pois provocam mudanças nos comportamentos das pessoas na forma de vislumbrar o mundo. Nesses tempos de mudanças, exige-se que os professores, urgentemente, compreendam e se preparem para saber lidar com condições de trabalho que afetam o rendimento e, consequentemente, a qualidade de vida no trabalho.

Neste entendimento, para Cury Junior (2012), o trabalho do professor não deve vincular-se apenas à sala de aula; os professores necessitam ampliar suas atividades para além de um ambiente restrito.

Ao longo do processo histórico, com as transformações globais, o ambiente de trabalho foi sendo remodelado, influenciando significativamente na saúde dos profissionais, principalmente no âmbito profissional da docência. Além disso, os professores estão constantemente expostos à situações de risco tanto físicos quanto mentais. A qualidade de vida no trabalho está associada a fatores psicológicos, organizacionais e políticos, condições estas fundamentais aos trabalhadores, pois estão relacionadas às oportunidades de progresso, com promoção pessoal e profissional.

Moreira et al. (2010) afirmam que as condições de trabalho dos professores da educação básica tendem a enfrentar situações de (des)favorecimento e desmotivação, o que implica em uma larga discussão a respeito da qualidade de vida no trabalho desse profissional da educação.

Apesar de o bem-estar de qualquer profissional estar associado à presença, ou ausência, de saúde, a qualidade de vida no trabalho desses indivíduos relaciona-se frequentemente à promoção de hábitos saudáveis e ao desempenho do trabalho, e deparase com alguns desafios afetos ao trabalho do professor. Segundo Cabral Júnior (2013, p. 12), tais desafios acabam por configurar impasses que dificultam a "melhoria da qualidade de vida no trabalho, como a falta de cultura e de interesse dos que se encontram na administração educação pública". Em linhas gerais, tais impasses ocorrem desde as 
|Alda Dantas do Rêgo | Adriana Leônidas de Oliveira |

condições básicas de trabalho até a ausência de políticas públicas importantes à viabilização da qualidade de vida no trabalho desses professores no ambiente escolar.

\section{METODOLOGIA}

Para a realização desta pesquisa, optou-se por um estudo bibliográfico classificado como revisão integrativa, a partir de Souza, Silva e Carvalho (2010). A revisão integrativa viabiliza uma síntese de conhecimento sobre estudos significativos a partir de diferentes metodologias. Este levantamento cobriu o período de publicações compreendido entre 2006 e 2016.

Utilizou-se o sistema informatizado de busca nas seguintes bases de dados: Literatura Latino-Americana e do Caribe em Ciências da Saúde (LILACS), Scientific Electronic Library Online (SCIELO) e Periódicos Capes: Revista Evidência e Revista Brasileira em Promoção da Saúde, identificados por meio da Biblioteca Virtual em Saúde (BVS). Esse portal é reconhecido por ser um espaço de integração de fontes de informações que promovem a democracia e a ampliação de acervos científicos e técnicos.

$\mathrm{Na}$ primeira fase, realizou-se uma busca simples utilizando as palavras-chave "qualidade de vida", "trabalho", "professor" e "educação básica". A escolha das palavraschave foi baseada em assuntos comuns relacionados à qualidade de vida no trabalho de professores nos últimos dez anos, em razão da sua importância para o mundo da pesquisa cientifica.

A partir dessa etapa inicial de busca, pode-se estabelecer critérios de inclusão dos resultados anteriores de acordo com o Quadro 1, a seguir:

Quadro 1 - Tipos de critérios estabelecidos para inclusão dos resultados da primeira fase

\begin{tabular}{|l|l|}
\hline Tipo & Critérios \\
\hline Palavras-chave & Qualidade de vida \\
& Trabalho \\
& Professor \\
& Educação Básica \\
\hline Base de Dados & $\begin{array}{l}\text { LILACS } \\
\text { SciELO } \\
\text { Periódicos Capes: Revista Evidência e Revista Brasileira } \\
\text { em promoção da Saúde }\end{array}$ \\
\hline Assunto & Qualidade de Vida no Trabalho de Professores \\
\hline Ano de publicação & De 2006 a 2016 \\
\hline Situação do texto & Completo \\
\hline Idioma da publicação & Brasil \\
\hline Tipo de documento & Artigos \\
\hline Fonte: A autora (2017). &
\end{tabular}


Conforme o Quadro 1, foi possível identificar um total de 75 estudos baseados nos critérios estabelecidos. Após, iniciou-se a verificação e a análise dos títulos, além de uma breve leitura dos resumos dos artigos selecionados em conformidade com o tema da pesquisa. Embora esses estudos sejam consideravelmente importantes para o meio acadêmico, poucos artigos foram mantidos para análise a partir dos resumos e para leitura integral de seu conteúdo, se de acordo com os critérios fixados.

Dessa forma, somaram-se 21 publicações elegíveis (LILACS, 5; SciELO, 12; Periódicos Capes, 4). Todos os artigos foram agrupados e analisados individualmente e os que não estavam em conformidade com o tema desta pesquisa foram excluídos, o que totalizou 17 artigos, restando apenas cinco artigos para leitura na íntegra, permitindo que o objetivo deste estudo fosse alcançado.

\section{DISCUSSÃO DOS RESULTADOS}

O resultado final desta revisão foi constituída por cinco artigos científicos selecionados pelos critérios de inclusão anteriormente estabelecidos. Destes, dois foram encontrados na base de dados SciELO, um na base LILACS e dois no Periódico Capes: Revista Evidência e Revista Brasileira em Promoção da Saúde. O Quadro 2 demonstra cada um dos artigos estudados de forma detalhada e como os dados foram analisados em termos descritivos, com o objetivo de apresentação pormenorizada das especificações nas quais os artigos foram categorizados. Foram utilizados os seguintes critérios: procedência, autoria e ano de publicação, a fim de corroborar com o ano de publicação do estudo, objetivo, método (este enfatizado pelo quantitativo), resumo sucinto dos resultados e considerações finais/conclusão dos estudos analisados. 
Dossiê: Diálogos interdisciplinares em Psicologia da Educação

|Qualidade de vida no trabalho de professores da Educação Básica: revisão integrativa|

|Alda Dantas do Rêgo | Adriana Leônidas de Oliveira|

Quadro 2 - Síntese dos artigos selecionados para revisão integrativa

\begin{tabular}{|c|c|c|c|c|c|}
\hline Título & Autoria & Objetivo & Método & Síntese dos Resultados & Conclusões \\
\hline $\begin{array}{l}\text { Qualidade de vida no } \\
\text { trabalho e perfil do estilo de } \\
\text { vida individual de } \\
\text { professores de Educação } \\
\text { Física ao longo da carreira } \\
\text { docente }\end{array}$ & $\begin{array}{l}\text { Moreira } \\
\text { et al. } \\
(2010)\end{array}$ & $\begin{array}{l}\text { Analisar a percepção de Qualidade de } \\
\text { Vida no Trabalho (QVT), o Estilo de } \\
\text { Vida (EV) e suas associações com os } \\
\text { Ciclos de Desenvolvimento } \\
\text { Profissional (CDP) dos professores de } \\
\text { Educação Física da rede estadual do } \\
\text { Paraná. }\end{array}$ & Quantitativo & $\begin{array}{l}\text { Os resultados revelaram que a maioria dos } \\
\text { professores está satisfeita com a QVT e apresenta } \\
\text { comportamento positivo quanto ao PEVI. }\end{array}$ & $\begin{array}{l}\text { Com o avanço na carreira docente, } \\
\text { aumenta a inspiração da QVT e os } \\
\text { comportamentos negativos do } \\
\text { PEVI, cuja maior preocupação é o } \\
\text { nível de atividade física. }\end{array}$ \\
\hline $\begin{array}{l}\text { Qualidade de Vida de } \\
\text { Professoras do Ensino } \\
\text { Básico da Rede Pública }\end{array}$ & $\begin{array}{l}\text { Tavares } \\
\text { et al. } \\
(2015)\end{array}$ & $\begin{array}{l}\text { Avaliar os aspectos associados à } \\
\text { qualidade de vida }(\mathrm{QV}) \text { de professoras } \\
\text { do ensino básico da rede pública de } \\
\text { Viçosa-MG, buscando relações com a } \\
\text { classe econômica. }\end{array}$ & Quantitativo & $\begin{array}{l}\text { A maioria das avaliadas se encontrava nas classes } \\
\text { econômicas B1/B2, com } 60,3 \% \text {. O escore médio } \\
\text { da QV geral foi de } 68,43(+11,69) \text { pontos, com } \\
\text { maiores valores para os domínios "relações } \\
\text { sociais" e "físico". }\end{array}$ & $\begin{array}{l}\text { A QVT foi considerada entre } \\
\text { regular e boa entre a população } \\
\text { estudada. }\end{array}$ \\
\hline $\begin{array}{l}\text { Qualidade de vida no } \\
\text { trabalho percebida por } \\
\text { professores de Educação } \\
\text { Física }\end{array}$ & $\begin{array}{l}\text { Both et } \\
\text { al. (2006) }\end{array}$ & $\begin{array}{l}\text { Verificar a validade e a fidedignidade da } \\
\text { "Escala de Avaliação da Qualidade de } \\
\text { Vida no Trabalho Percebida por } \\
\text { Professores de Educação Física do } \\
\text { Ensino Fundamental e Médio" (QVT- } \\
\text { PEF). }\end{array}$ & Quantitativo & $\begin{array}{l}\text { Os resultados da QVT-PEF apresentam níveis } \\
\text { aceitáveis de reprodutibilidade, consistência } \\
\text { interna e de validade de conteúdo, justificando a } \\
\text { sua utilização em pesquisas que analisem a } \\
\text { qualidade de vida de professores de Educação } \\
\text { Física Escolar. }\end{array}$ & $\begin{array}{l}\text { Entre os níveis de aceitações, } \\
\text { revelou-se a existência de um } \\
\text { elevado nível de QVT. }\end{array}$ \\
\hline $\begin{array}{l}\text { O trabalho docente e a } \\
\text { qualidade de vida dos } \\
\text { professores na educação } \\
\text { básica }\end{array}$ & $\begin{array}{l}\text { Pereira et } \\
\text { al. (2013) }\end{array}$ & $\begin{array}{l}\text { Investigar alguns fatores relacionados à } \\
\text { qualidade de vida de professores de } \\
\text { educação básica do município de } \\
\text { Florianópolis, SC, Brasil, considerando } \\
\text { as características do trabalho docente. }\end{array}$ & Quantitativa & $\begin{array}{l}\text { Os professores com maior carga horária semanal } \\
\text { e aqueles da rede estadual de ensino apresentaram } \\
\text { menores índices de qualidade de vida em todos os } \\
\text { domínios investigados. }\end{array}$ & $\begin{array}{l}\text { A redução da carga horária parece } \\
\text { ser o principal fator associado aos } \\
\text { menores índices de QVT. }\end{array}$ \\
\hline $\begin{array}{l}\text { Qualidade } \\
\text { trabalho e vida no } \\
\text { docentes }\end{array}$ & $\begin{array}{l}\text { Cury } \\
\text { Junior } \\
(2012)\end{array}$ & $\begin{array}{l}\text { Analisar o universo pesquisado de } \\
\text { professores regentes (concursados e } \\
\text { efetivos) no Ensino Fundamental }\left(6^{\circ}\right. \\
\text { ao } 9^{\circ} \text { ano do ciclo dos anos finais), que } \\
\text { atuam há mais de } 15 \text { anos em Escolas } \\
\text { Estaduais na cidade de Araxá, MG. }\end{array}$ & Qualitativa & $\begin{array}{l}\text { Com base nos resultados, tem-se que, a partir do } \\
\text { mundo, de seu cotidiano e de sua história, a } \\
\text { prática e a subjetividades docentes vão se } \\
\text { construindo. Pelo enfrentamento com a realidade, } \\
\text { elas são afetadas pelas condições de trabalho, } \\
\text { novas exigências educacionais, pelo quase } \\
\text { inexistente ou mal aproveitado tempo livre para o } \\
\text { lazer e relações sociais extra-trabalho docente, } \\
\text { capazes de potencializar novas posturas que } \\
\text { propiciem qualidade de vida desses profissionais. }\end{array}$ & $\begin{array}{l}\text { O estudo apontou a importância, a } \\
\text { necessidade e a possibilidade de os } \\
\text { professores se reconfigurarem, } \\
\text { mediante exigências impostas à } \\
\text { profissão docente. }\end{array}$ \\
\hline
\end{tabular}

Fonte: A autora (2017).

\begin{tabular}{llllll} 
InterEspaço & Grajaú/MA & v. 3, n. 11 & p. 375-388 & dez. 2017 & Página 382 \\
\hline
\end{tabular}


Dossiê: Diálogos interdisciplinares em Psicologia da Educação

|Qualidade de vida no trabalho de professores da Educação Básica: revisão integrativa|

|Alda Dantas do Rêgo | Adriana Leônidas de Oliveira|

Analisando, em linhas gerais, os objetivos dos artigos revisados, quase todas as publicações tiveram suas pretensões atingidas, embora estejam relatando assuntos comuns. Entretanto, foram identificados aspectos associados e fatores relacionados à qualidade de vida dos professores, assim como as percepções, estilo de vida, validação e fidedignidade de qualidade de vida no trabalho afetos aos profissionais da educação básica, o que permite a conclusão de que os objetivos desses artigos apresentam enfoques distintos e que tiveram como foco populacional os professores da educação básica da rede pública.

Quanto aos títulos dos artigos analisados, observou-se que foram pesquisas direcionadas à profissão docente e à sua qualidade de vida, com foco nos danos dos grandes centros urbanos. No que concerne às autorias, o que se percebe, em sua maioria, são artigos publicados com coautorias (com pelos menos três ou mais nomes); em análises gerais, observou-se que as publicações com coautorias tendem a se destacar no cenário dos estudos científicos.

Com relação aos métodos dos artigos analisados, três deles se enquadraram no método quantitativo e apenas um apresentou metodologia qualitativa. Todos os estudos utilizaram um ou mais instrumentos para coleta dos dados. No tocante ao tema qualidade de vida no trabalho, dois dos estudos empregaram medidas/instrumentos para construir seus resultados. Foram utilizados a Escala de Avaliação da Qualidade de Vida no Trabalho (QVT-PEF), um outro lançou mão de um recorte temporal e os dois últimos utilizaram os instrumentos World Health Organization Quality of Life/BREF (WHOQOL-BREF), recomendado pela Organização Mundial da Saúde para avaliação da qualidade de vida da nação.

O estudo publicado por Moreira et al. (2010) buscou descrever a percepção da qualidade de vida no trabalho, o estilo de vida associado ao ciclo de desenvolvimento profissional dos professores de Educação Física de escola da rede estadual do Paraná. Foram investigados 4.770 professores com a utilização dos instrumentos Escala de Avaliação da Qualidade de Vida no Trabalho (QVT-PEF) e Perfil do Estilo de Vida Individual (PEVI). Os resultados mostraram que seis em cada dez pesquisados estão satisfeitos com a qualidade de vida no trabalho e apresentam perfil positivo sobre o estilo de vida. Nota-se que o resumo desse artigo apresenta de forma clara e sucinta o desfecho da pesquisa. Os autores identificaram que a maior preocupação refere-se aos ciclos de desenvolvimento que apresentam insatisfação relacionada aos componentes da qualidade de vida no trabalho, e recomendam que sejam adotadas políticas públicas em prol do 
Dossiê: Diálogos interdisciplinares em Psicologia da Educação

|Qualidade de vida no trabalho de professores da Educação Básica: revisão integrativa|

|Alda Dantas do Rêgo | Adriana Leônidas de Oliveira|

desenvolvimento profissional e da valorização do magistério. Sugerem ainda uma logística laboral e a implementação de plano na carreira de docência.

Tavares et al. (2015) investigaram os aspectos da qualidade de vida dos professores associados à classe econômica. Embora o objetivo da pesquisa tenha sido a avaliação de aspectos relacionados à Qualidade de Vida, por meio de estudo descritivo, os instrumentos Critério de Classificação Econômica (CCEB) e World Health Organization Quality of Life/bref (WHOQOL/breve) utilizados identificaram que os pesquisados possuem apoio social, permitindo que os efeitos da qualidade de vida influenciem positivamente na sua satisfação quanto às relações pessoais. Na comparação dos domínios da Qualidade de Vida e da Classe Econômica, houve uma fraca concexão entre as "relações sociais" e a "carga horária semanal"; afetaram negativamente a Qualidade de Vida dos pesquisados os domínios “meio ambiente" e "psicológico" relacionados à menor classe econômica.

Os autores também reconsideram a possibilidade de aplicabilidades de políticas públicas e a implantação de planejamento de ações de promoção de saúde mental, que visem melhores acessos aos domínios de qualidade de vida dos professores. Ainda sobre o conhecimento científico deste constructo, os indicadores de qualidade de vida identificados evidenciam uma correlação dos componentes característicos da qualidade de vida no trabalho, que é uma ação positiva e motivadora da qualidade de vida geral.

Já no estudo publicado por Both et al. (2006), investigou-se a validação de instrumento na percepção dos professores sobre a qualidade de vida, da educação básica no sentido de aproximação da linguagem, esta mais simples para a melhoria e a adaptação dos itens. Para a validação do instrumento, foram consultados 19 pesquisados; obteve-se um nível de confiabilidade superior a 70\%, apresentando elevado índice de concordância entre os consultados.

O instrumento utilizado contempla todas as dimensões afetas à qualidade de vida no trabalho proposto por Walton (1973), desde a dimensão remuneração até a relevância social de uma organização. Os autores entendem como necessário um aperfeiçoamento no instrumento (Escala de Avaliação da Qualidade de Vida no Trabalho - QVT-PEF) utilizado com professores de Educação Física do ensino fundamental e médio de Florianópolis, SC. Ressalta-se que esse estudo buscou apenas verificar se válido e fidedigno o instrumento a partir da percepção dos pesquisados. Para sua validação, utilizou-se a consistência interna pelo coeficiente alfa de Cronbach $(0,9482)$, considerado elevado na avaliação. 
Dossiê: Diálogos interdisciplinares em Psicologia da Educação

|Qualidade de vida no trabalho de professores da Educação Básica: revisão integrativa|

|Alda Dantas do Rêgo | Adriana Leônidas de Oliveira|

Quanto ao estudo de Pereira et al. (2014), foram encontradas evidências semelhantes às do estudo realizado por Ferreira et al. (2015) no que se refere aos domínios da qualidade de vida dos professores. Ambas as pesquisas utilizaram o instrumento Whoqol-bref, mas com critérios de estudos diferentes. $\mathrm{Na}$ investigação realizada por Pereira et al. (2014), os professores da educação básica com maior carga horária semanal apresentam menor índice de qualidade de vida em todos os domínios avaliados.

Em comparação aos participantes (efetivos e substitutos), os escores superiores nas análises de qualidade de vida estão a favor dos professores substitutos em razão do número de carga horária exercida, que é menor em comparação ao do professor efetivo. A amostra analisada foi composta por 349 professores selecionados de forma aleatória, alcançando 18 escolas da cidade de Florianópolis, SC.

Os autores ainda ressaltam que os professores em sala de aula possuem escores menores em comparação àqueles que exercem cargos de direção. Os pesquisados com maior carga horária e a rede de ensino foram as variáveis que demonstraram importância relevante nas análises de qualidade de vida, ficando evidente que a Qualidade de Vida diminui na medida em que aumenta a carga horária trabalhada. Pereira et al. (2014) recomendam novos estudos que investiguem a relação da qualidade de vida com a violência dos alunos.

Por fim, o último artigo analisado (CURY JUNIOR, 2012) foi um recorte que abordou o tema “formação" e "trabalho docentes". Nesse estudo, o autor apresentou uma pesquisa de boa qualidade na fundamentação teórica; o resumo detalhou bem o descrito do trabalho e os demais pontos estavam de acordo com o corpo da pesquisa. Com essa investigação, Cury Junior (2012) destaca ter construído um conhecimento que pode favorecer as questões relacionadas à formação e ao trabalho docente. Por se tratar de uma pesquisa bibliográfica, os resultados apresentados baseiam-se em constructos vinculados à qualidade de vida no trabalho que necessitam aproximar os professores comprometidos com as práticas reflexivas das ações da formação docente.

O estudo deixa evidente que diversos fatores interferem na satisfação do indivíduo, prejudicando seu desempenho no trabalho e em todas as dimensões da sua qualidade de vida no trabalho.

\section{CONSIDERAÇÕES FINAIS}


Dossiê: Diálogos interdisciplinares em Psicologia da Educação

|Qualidade de vida no trabalho de professores da Educação Básica: revisão integrativa|

|Alda Dantas do Rêgo | Adriana Leônidas de Oliveira|

O presente estudo teve como objetivo verificar as publicações nacionais relacionadas à qualidade de vida no trabalho de professores de educação básica, que atuam na rede pública. As condições precárias de trabalho, a carga horária excessiva e o pouco tempo para lazer a que é submetida a maioria dos professores são os fatores que comprometem a qualidade de vida no trabalho desse profissional.

Pelos artigos analisados, embora existam pesquisas sobre a qualidade de vida e a qualidade de vida no trabalho, são poucas as produções que avaliam os aspectos econômicos e as condições de trabalho de professores fora dos grandes centros urbanos.

Dessa forma, é necessário criar ações/estratégias que promovam a qualidade de vida e a qualidade de vida no trabalho, com ênfase na qualidade de vida no trabalho pelo fato de ocorrer diretamente no espaço/ambiente de trabalho onde os professores passam a maior parte de suas vidas. Assim, o estudo realizado sobre a Qualidade de Vida no Trabalho de professores por meio da revisão de literatura evidenciou a importância de imprimir maior credibilidade ao assunto.

Os números de pesquisas desenvolvidas sobre qualidade de vida no trabalho de professores se mostram reduzidos em comparação ao tema gerador - Qualidade de Vida. Este sim apresenta inúmeros estudos que abrangem quase todos os profissionais. Portanto, considerando a quantidade de artigos selecionados e revisados para esta pesquisa, percebeu-se que as publicações nacionais representam uma porcentagem mínima em relação às publicações internacionais. São fundamentais mais produções científicas sobre o tema.

Este estudo, realizado por meio de uma revisão integrativa, contribuiu para a obtenção de conhecimento, de aprendizagem e de uma efetiva reciprocidade com as informações sobre o assunto pesquisado. Assim, tendo em vista a importância das pesquisas sobre a qualidade de vida no trabalho de professores, sugerem-se novos estudos com metodologia e técnica que ampliem maior número de informações nas bases de dados científicos e permitam discussões mais aprofundadas sobre a Qualidade de Vida no Trabalho de professores da educação básica.

\section{REFERÊNCIAS}

BOTH, J. et al. Qualidade de vida no trabalho percebida por professores de Educação Física. Rev. Bras. Cineantropom. Desempenho Hum., v. 8, n. 2, p. 45-52, 2006. Disponível em: < http://www.scielo.br/pdf/rbcdh/v12n6/v12n6a07.pdf > . Acesso em: 25 jan. 2017. 
|Alda Dantas do Rêgo | Adriana Leônidas de Oliveira |

CABRAL JÚNIOR, U. B. O ambiente de Trabalho dos profissionais de educação. In: CABRAL JÚNIOR, U. B. et al. (Org). Qualidade de Vida no ambiente de trabalho de profissionais da Educação. Rio de Janeiro: Ed. DP Editora Ltda., 2013. p. 11-194.

CURY JUNIOR, C. H. Qualidade de vida no trabalho e subjetividades docentes. Revista Evidência, v. 6, n. 6, p. 89-110, 2012. Disponível em: <http://www.uniaraxa.edu.br/ojs/index.php/evidencia/article/view/211>. Acesso em: 26 jan. 2017.

FRANÇA, A. C. Qualidade de vida no trabalho: conceitos, abordagens, inovações e desafios nas empresas brasileira. Revista Brasileira de Medicina Psicossomática, Rio de Janeiro, v. 1, n. 2, p. 79-83, abr./mai./jun. 1997. Disponível em:

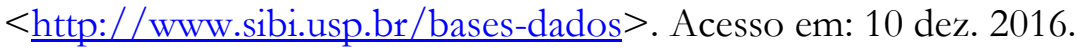

HOLMES, E. S. et al. (2014). Síndrome de Burnout em enfermeiros na atenção básica: repercussão na qualidade de vida. Revista de pesquisa: cuidado é fundamental, Rio de Janeiro, v. 6, n. 4, p. 1384-1395. Disponível em: < http://www.seer.unirio.br/index.php/cuidadofundamental/article/view/3311/pdf.656>. Acesso em: 23 jan. 2017.

MENDONÇA, S. H. A.; ARAÚJO, L. S. Esgotamento profissional e qualidade de vida no trabalho: uma revisão integrativa. Psicologias, v. 2, p. 01-19, 2016. Disponível em: $<$ http://revistas.ufac.br/revista/index.php/psi/article/view/472>. Acesso em: $02 \mathrm{fev}$. 2017.

MOREIRA, H. de R. et al. Qualidade de vida no trabalho e perfil do estilo de vida individual de professores de Educação Física ao longo da carreira docente. Motriz: Revista de Educação Física, v. 16, n. 4, p. 900-912, 2010. Disponível em: < http://dx.doi.org/10.5016/1980-6574.2010v16n4p900>. Acesso em: 23 jan. 2017.

Qualidade de vida no trabalho e síndrome de Burnout em professores de educação física do estado do Rio Grande do Sul, Brasil. Revista Brasileira de Atividade Física \& Saúde, v. 14, n. 2, p. 115-122. Disponível em:

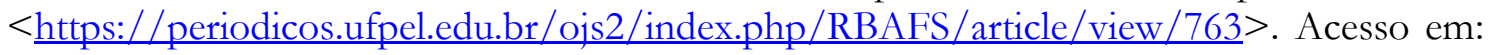
23 jan. 2017.

PEREIRA, É. F. et al. O trabalho docente e a qualidade de vida dos professores na educação básica. Revista de Salúd Publica, v. 16, n. 2, p. 221-231, 2014. Disponível em: < https://www.scielosp.org/pdf/rsap/v16n2/v16n2a06.pdf>. Acesso em: 23 jan. 2017.

RODRIGUES, M. V. C. Qualidade de vida no trabalho: evolução e análise no nível gerencial. 15. ed. atualizada e ampliada. Petrópolis, RJ: Vozes, 2016.

RUEDA, F. J. M.; LIMA, R. C. de; RAAD, A. J. Qualidade de vida e satisfação no trabalho: relação entre escalas que avaliam os construtos. Boletim de Psicologia, v. 64, n. 141, p. 129-141, 2014. Disponível em: < https://goo.gl/EU3bwE>. Acesso em: 02 fev. 2017.

SOUZA, M. T.; SILVA, M. D.; CARVALHO, R. Revisão integrativa: o que é e como fazer. Einstein, v. 8 , n. 1, p. 102-106, 2010. Disponível em: 
Dossiê: Diálogos interdisciplinares em Psicologia da Educação

|Qualidade de vida no trabalho de professores da Educação Básica: revisão integrativa|

|Alda Dantas do Rêgo | Adriana Leônidas de Oliveira|

$<$ http://www.scielo.br/pdf/eins/v8n1/pt 1679-4508-eins-8-1-0102>. Acesso em: 20 jan. 2017.

TABELEÃO, V. P.; TOMASI, E.; NEVES, S. F. Qualidade de vida e esgotamento profissional entre docentes da rede pública de Ensino Médio e Fundamental no Sul do Brasil. Cadernos de Saúde Pública, Rio de Janeiro, v. 27, n. 12, p. 2401-2408, 2011. Disponível em: < http://dx.doi.org/10.1590/S0102-311X2011001200011>. Acesso em: 23 jan. 2017.

TAVARES, F. et al. Qualidade de vida de professoras do ensino básico da rede pública. Revista Brasileira em Promoção da Saúde, v. 28, n. 2, p. 191-197, 2015. Disponível em: < $\underline{\text { http://periodicos.unifor.br/RBPS/article/view/3448> }}$. Acesso em: 25 jan. 2017. 